\title{
SISTEM INFORMASI E-COMMERCE GUNA MEMBANTU PENJUALAN DI TOKO VANIA FURNITURE
}

\section{Information Systems E-Commerce for Helping Sales on Vania Furniture Store}

\author{
Windra Halim ${ }^{1)}$, Okto Jonathan ${ }^{1)}$ \\ ${ }^{1)}$ Sistem Informasi/Fakultas Teknologi dan Desain, Universitas Bunda Mulia
}

Diterima 03 Juni 2017 / Disetujui 31 Juli 2018

\begin{abstract}
Vania Furniture Store is a shop that sells interior furniture. This shop is stir in the sale of various furniture tools such as sofas, tables, chairs, cabinets, and others. Vania Furniture Store still uses manual way to sell and market its products. To improve business development at Vania Furniture Store Then designed E-Commerce application to handle the problem. The method used to obtain the data is divided into two, namely interview and literature study The results of the method used, the data obtained in the form of business processes running on prospective customers, business processes on the customer remains, and the sales note from Vania Furniture Store. In making this research as for the results obtained in the form of E-Commerce application to handle problems in business development at Vania Furniture Store. Based on the design of E-Commerce Application on Vania Furniture Store, it is concluded that the application made has been successful in giving the web based application display process so that it has been implemented web based system can be very supportive for the expansion of business range in Vania Furniture Store. With the creation of this E-Commerce application is expected to run well on Vania Furniture Store.
\end{abstract}

Keywords: E-Commerce, Business development, Web-Based.

\begin{abstract}
ABSTRAK
Toko Vania Furniture adalah toko yang begerak dibidang penjualan interior furniture. Toko ini begerak di bidang penjualan berbagai alat furniture seperti sofa, meja, kursi, lemari, dan lain - lain. Toko Vania Furniture masih menggunakan cara manual dalam menjual dan memasarkan produknya. Untuk meningkatkan perkembangan bisnis pada Toko Vania Furniture Maka dirancang aplikasi E-Commerce untuk menangani masalah tersebut. Metode yang digunakan untuk memperoleh data terbagi menjadi dua yaitu wawancara dan studi kepustakaan. Hasil dari metode yang di gunakan, data yang di peroleh berupa proses bisnis berjalan pada calon customer, proses bisnis pada customer tetap, dan nota penjualan dari Toko Vania Furniture. Dalam pembuatan penelitian ini adapun hasil yang didapat berupa aplikasi ECommerce untuk menangani masalah dalam pengembangan bisnis pada Toko Vania Furniture. Berdasarkan perancangan Aplikasi E-Commerce pada Toko Vania Furniture, diperoleh kesimpulan bahwa aplikasi yang dibuat telah berhasil memberikan proses tampilan aplikasi berbasis web sehngga dengan sudah di terapkannya sistem berbasis web dapat sangat menunjang untuk perluasan jangkauan bisnis pada Toko Vania Furniture. Dengan dibuatnya aplikasi E-Commerce ini diharapkan dapat berjalan dengan baik pada Toko Vania Furniture.

Kata Kunci: E-Commerce, Perkembangan Bisnis, Berbasis Web.
\end{abstract}




\section{PENDAHULUAN}

Dalam era globalisasi ini, tingkat penggunaan teknologi semakin lama semakin meningkat. Begitu juga dengan tingkat penggunaan internet semakin lama semakin banyak perusahaan yang menggunakanya dalam menjalankan aktivitas perusahaan mereka. Internet juga menjadi salah satu hal yang sangat berkembang dewasa ini dimana hampir semua orang mengenal internet. Internet itu sendiri dewasa ini tidak hanya digunakan untuk berhubungan sosial saja, salah satunya e-commerce. Banyak toko - toko atau perusahaan besar yang mengembangkan e-commerce untuk menunjang kebutuhan dan memperlebar sayap bisnisnya.

Banyak sekali manfaat yang didapatkan oleh suatu bisnis yang menggunakan e-commerce, sebagai salah satu contohnya e-commerce dapat digunakan sebagai media promosi tambahan dan untuk menjangkau banyak konsumen. Selain itu dengan adanya $e$ commerce, promosi dan penjualan dapat di lakukan kapan saja dengan biaya operasional yang cukup rendah.

Toko Vania Furniture adalah toko yang begerak dibidang penjualan interior furniture. Toko ini begerak di bidang penjualan berbagai alat furniture seperti sofa, meja, kursi, lemari, dan lain - lain.

Toko Vania Furniture masih menggunakan sistem pemasaran dan penjualan manual ke perusahaan lain yaitu dari mulut ke mulut untuk memasarkan dan menjual produk - produknya. Sehingga jumlah pelanggan sulit untuk meningkat, karena keterbatasan informasi yang di dapat oleh customer mengenai produk. Toko Vania Furniture hanya menjual produknya ke perusahaan sejenis. Oleh karena itu dibutuhkan aplikasi yang mampu mengembangkan bisnisnya secara online. secara online.

*Korespondensi Penulis:

E-mail: wizzly.wh@gmail.com

\section{STUDI PUSTAKA}

\section{E-Commerce (Electronic Commerce)}

Mendefinisikan proses membeli, menjual, mentransfer, atau menukarkan produk, jasa ,atau informasi melalui jaringan komputer termasuk internet (Rainer, Prince \& Cegielski, 2015).

Berikut tipe-tipe E-commerce menurut (Rainer, Prince \& Cegielski, 2015) E-commerce bisa di konduksikan diantara dan beberapa kelompok yang bervariasi, secara umum ada enam tipe E-commerce:

1. Business-to-consumer electronic commerce (B2C). Dalam B2C, penjualnya adalah organisasi, sedangkan pembelinya adalah individu.

2. Business-to-business electronic commerce (B2B). Dalam transaksi B2B, keduanya baik penjual maupun pembeli merupakan organisasi bisnis.

3. Consumer-to-consumer electronic commerce $(\mathrm{C} 2 \mathrm{C})$. Dalam $\mathrm{C} 2 \mathrm{C}$ (atau biasanya disebut customer-to-customer), seorang individu menjual produk atau jasa ke individu lain.

4. Business-to-employee (B2E). Dalam $\mathrm{B} 2 \mathrm{E}$, sebuah organisasi menggunakan E-commerce secara internal untuk menyediakan informasi dan pelayanan untuk karyawannya sendiri.

5. E-government. E-government secara umum adalah penggunaan teknologi internet sedangkan E-commerce secara tertentu untuk mengirim informasi dan layanan publik ke masyarakat (disebut government-to-citizen atau G2C ECommerce) dan untuk rekan bisnis dan pemasok (disebut government-tobusiness atau G2B E-Commerce).

6. Mobile commerce (M-commerce). Periode E-commerce mengacu pada $E$ commerce yang di lakukan secara menyeluruh dalam lingkungan nirkabel.

Systems Development Life Cycle (SDLC)

SDLC adalah proses untuk mengartikan bagaimana sistem informasi bisa mendukung kebutuhan bisnis berdasarkan desain sistem, merancang, dan penyampaian pada user (Tegarden, Dennis \& Wixom, 2013). 
Menurut (Tegarden, Dennis \& Wixom, 2013) System Development Life Cycle Waterfall Model di bagi menjadi 4, yaitu:

1. Planning adalah proses fundemantal untuk mengerti mengapa sistem informasi seharusnya membangun dan menentukan bagaimana tim proyek akan membangun proyek tersebut.

2. Analysis untuk menjawab pertanyaan siapa yang akan menggunakan sistem, apa yang akan di lakukan sistem,dimana dan kapan sistem tersebut akan digunakan.

3. Design menentukan bagaimana sistem akan beroperasi, pada area hardware, software, dan jaringan infrastruktur. User interface, forms, dan reports. Program spesifik, database dan file-file yang akan di butuhkan.

4. Implementation tahap terakhir dalam SDLC adalah tahap implementasi, dimana sistem sebenarnya dibangun atau dibeli, dalam hal desain paket perangkat lunak. Ini adalah fase yang biasanya mendapat perhatian yang besar, karena bagi sebagian besar dari proses pembangunan, karena disini kita mulai berurusan dengan pemilihan perangkat keras dan penyusunan perangkat lunak aplikasi (pengkodean atau coding), dilanjutkan dengan fase implementasi yaitu proses delivery-nya kepada pengguna.

\section{Unified Modelling Language (UML)}

UML adalah sebuah kumpulan standar dari teknik pembuatan diagram yang menyediakan sebuah representasi grafis yang cukup kaya untuk memodelkan banyak sistem pengembangan proyek dari analisis menuju implementasi (Tegarden, Dennis \& Wixom, 2013).

Namun demikian model-model itu dapat dikelompokkan berdasarkan sifatnya yaitu statis atau dinamis. Jenis diagram itu antara lain: (Herlawati \& Widodo, 2011)

1. Use Case Diagram untuk memodelkan proses bisnis.

2. Conceptual Diagram untuk memodelkan konsep-konsep yang ada di dalam aplikasi.
3. Sequence Diagram untuk memodelkan pengiriman pesan (message) antar objek.

4. Collaboration Diagram untuk memodelkan interaksi antar objek.

5. State Diagram untuk memodelkan perilaku objects di dalam sistem.

6. Activity Diagram untuk memodelkan perilaku Use Case dan objek di dalam sistem.

7. Class Diagram untuk memodelkan struktur kelas.

8. Object Diagram untuk memodelkan struktur objek.

9. Component Diagram untuk memodelkan komponen objek.

10.Deployment Diagram untuk memodelkan distribusi aplikasi.

\section{Entity Relationship Diagram (ERD)}

Database relasional didasarkan pada koleksi tabel dengan setiap tabel yang memiliki primary key - field atau fields yang nilainya unik untuk setiap baris tabel. tabel saling terkait satu sama lain dengan menempatkan primary key dari satu tabel ke dalam tabel terkait sebagai foreign key (Tegarden, Dennis \& Wixom, 2013).

\section{CodeIgniter}

CodeIgniter (disebut sebagai CI) adalah Framework Application Development, atau alat bantu untuk orangorang yang membuat situs web dan aplikasi web PHP. CodeIgniter adalah kerangka kerangka pengembangan aplikasi yang cerdas, dengan Performa tinggi dan fleksibel dan low footprint (Orr \& Zadik, 2013).

MVC (Model, View, Controller) Konsep MVC adalah pola pengembangan atau kerangka aplikasi untuk sebuah user interface komputer yang memisahkan representasi informasi dari interaksi pengguna. MVC telah diadopsi sebagai arsitektur yang sukses untuk web perkembangan aplikasi. Model terdiri dari data aplikasi dan menyediakan layanan untuk memanipulasi. Controller menangani aturan dan menjalankan permintaan untuk model dan view. Controller menengahi antara input, kebanyakan diterima dari pengguna yang berinteraksi dengan web 
browser yang dieksekusi yang diberikan view (Orr \& Zadik, 2013).

\section{Referensi Penelitian Terdahulu}

Penelitian pertama yang pernah dilakukan oleh Sandy Kosasi (2015) yang berjudul "Perancangan Sistem Informasi Ecommerce untuk Memperluas Pasar Produk Oleh-Oleh Khas Pontianak". Tujuan penelitian adalah menghasilkan sistem yang dapat memberikan kemudahan mengenalkan dan menjual semua produk oleh-oleh khas dari Kota Pontianak secara global.

Penelitian kedua dilakukan oleh Sandy Kosasi (2015) yang berjudul "Perancangan Sistem E-commerce Untuk Produk Pembuatan Kue". Tujuan penelitian adalah sistem E-Commerce melalui integrasi database dan membina hubungan dengan pelanggan sehingga dapat memperlancar aliran informasi dan keputusan untuk memperluas pangsa pasar.

\section{METODOLOGI PENELITIAN}

Toko Vania Furniture adalah suatu toko yang berlatar belakang penjualan furniture di daerah Bandar lampung. Toko ini merupakan toko yang di buat sendiri oleh pemiliknya. Toko Vania Furniture menjual berbagai jenis furniture.Untuk saat ini Toko Vania Furniture hanya menjual produk nya ke perusahaan - perusahaan.

Toko ini sudah berdiri sejak 2 tahun lalu. Toko Vania Furniture terletak di Jalan Merbau Nomor 191 Bandar Lampung, Tanjung Karang, Kelurahan Tanjung Raya.

\section{Langkah-Langkah Penelitian}

Peneliti menggunakan langkahlangkah dibawah ini untuk mengembangkan seluruh hasil penelitian:

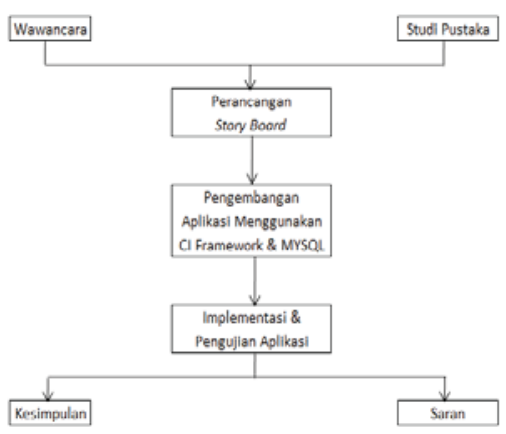

Gambar 1. Langkah-Langkah Penelitian

\section{Use Case Diagram}

Berikut ini adalah gambar usecase diagram pada toko Vania Furniture.

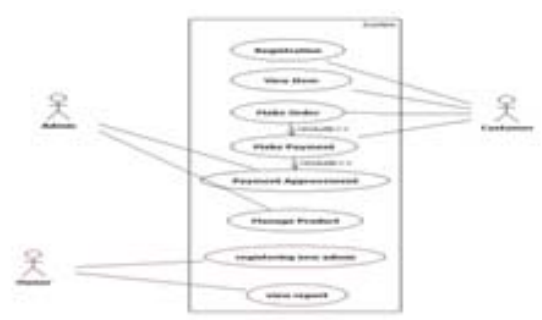

Gambar 2. Usecase Diagram

Gambar 2 merupakan usecase diagram proses bisnis yang di usulkan, usecase diagram tersebut terdari dari 3 aktor, yaitu admin, customer dan owner. Sebelum customer dapat mengorder barang, maka customer harus register terlebih dahulu, setelah itu barulah customer dapat melihat barang dan memilih barang yang di inginkan, setelah selesai memilih barang make customer mengorder barang tersebut dan membayar tagihan dari pemesanannya. Tugas admin yaitu mengapprove pembayaran dari customer, dan memanage barang-barang berupa dari pengaturan barang, kategori, dan konfirmasi pembayaran dari customer. Tugas Owner yaitu mengecek laporan penjualan dan mendaftarkan akun admin baru

\section{Activity Diagram}

Berikut ini adalah gambar activity diagram pada toko Vania Furniture. 


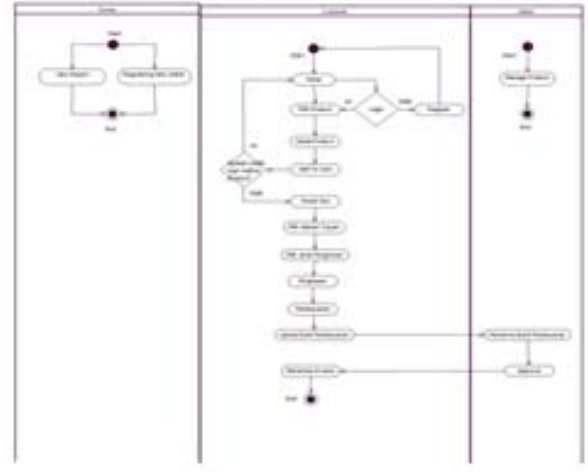

Gambar 3. Activity Diagram

Gambar 3 merupakan activity diagram proses bisnis yang di usulkan, activity diagram tersebut terdari dari 3 swimlane, yaitu admin, customer dan owner. Tugas dari owner yaitu melihat laporan penjualan dan mendaftarkan akun admin baru. Tugas dari customer yaitu memilih produk, setelah customer memilih produk yang diinginkan barulah customer memilih tujuan untuk pengiriman dan pemilihan jenis tarif, setelah selesai memilih tarif barulah customer dapat mengorder produk yang di inginkan dan melakukan pembayaran. Setelah customer melakukan pembayaran maka customer akan menunggu proses approvement yang di lakukan oleh admin, setelah pembayaran di aprrove oleh admin barulah customer mendapatkan invoice. Tugas dari admin adalah mengapprove pembayaran dari customer dan mengatur pengelolaan produk.

\section{Class Diagram}

Berikut ini adalah gambar class diagram pada toko Vania Furniture.

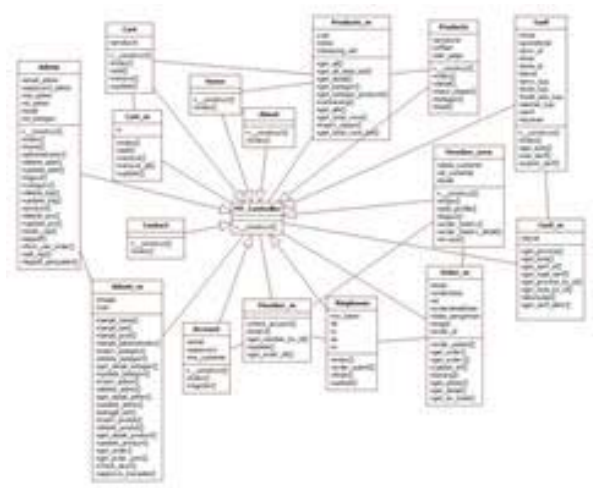

Gambar 4. Class Diagram
Gambar 4 merupakan class diagram yang di usulkan, class diagram tersebut teridri dari, admin, admin_m, contact, cart, cart_m, about, home, products, products_m, member_m, account, member_area, ringkasan, tarif, order_m, tarif_m, dan MY_Controller. setiap class memiliki masing-masing method dan beberapa atribut. Method berisikan tentang function atau action dari class tersebut. sedangkan atribut merupakan variabel tambahan yang berfungsi untuk menampung data.

\section{Entity Relationship Diagram (ERD)}

Berikut ini adalah gambar entity relationship diagram pada toko Vania Furniture:

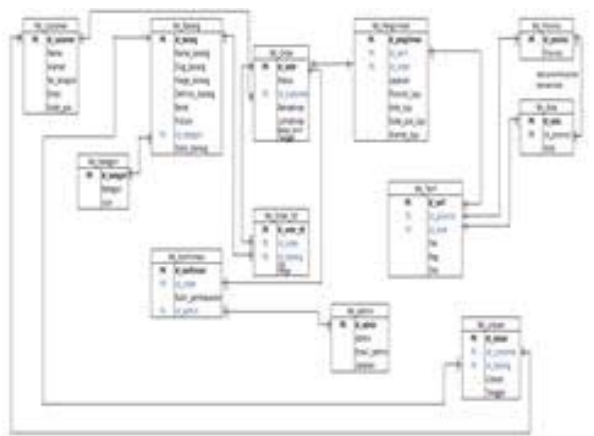

Gambar 5. Entity Relationship Diagram

\section{Analisa Perancangan}

Berikut ini adalah perancangan desain aplikasi e-commerce pada toko Vania Furniture:

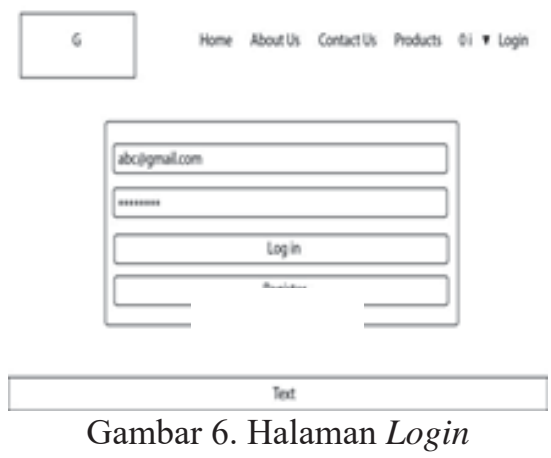

Pada tampilan halaman login ini menampilkan tampilan mengenai form untuk akses customer ke dalam situs ecommerce Vania Furniture. Data yang di perlukan untuk login customer berupa email dan password akun customer. 


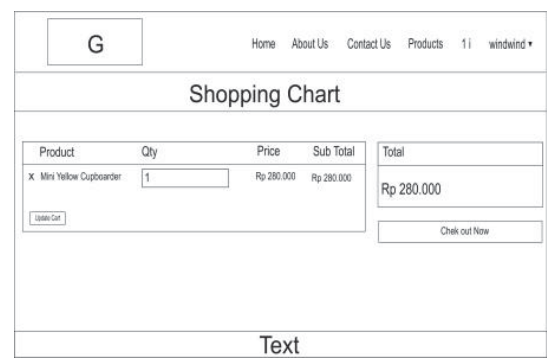

Gambar 7. Halaman Shopping Chart

Pada tampilan halaman shopping chart ini menampilkan tampilan mengenai produk yang sudah di pilih oleh customer. Terdapat juga informasi mengenai nama jumlah, harga, subtotal, dan total harga. Selain itu customer juga dapat merubah jumlah produk yang di inginkan dan menghapus daftar produknya yang tidak di ingikan. Navigasi check out now untuk menampilkan proses transaksi berikutnya.

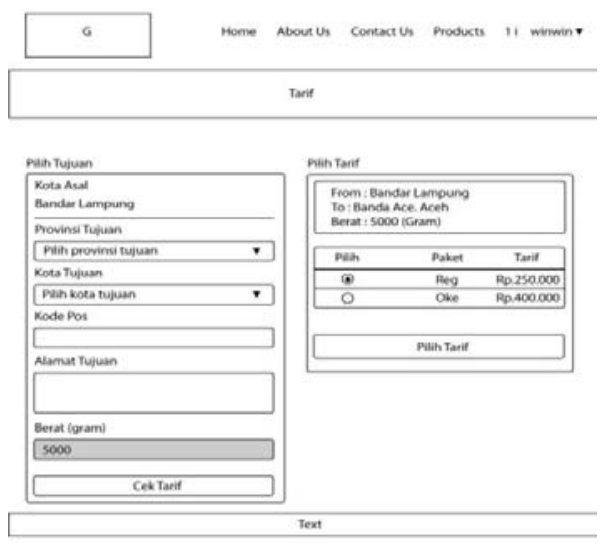

Gambar 8. Halaman Tarif

Pada tampilan halaman tarif ini menampilkan tampilan mengenai informasi tentang tempat asal pengiriman ke tempat tujuan pengiriman, dan pemilihan paket pengiriman. Customer bebas memilih pilihan tarif berdasarkan tarif yang sudah di sediakan.

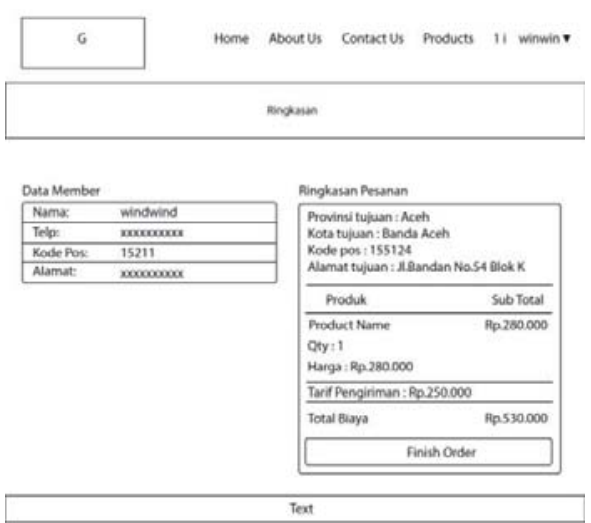

Gambar 9. Halaman Ringkasan

Pada tampilan halaman ringkasan ini menampilkan tampilan mengenai informasi tentang data customer, data berupa nama, nomor telepon, kode pos, dan alamat customer pemesan. Data yang di tampilkan pada ringkasan pesanan berupa provinsi tujuan, kota tujuan, kode pos, alamat tujuan, nama produk, quantity, harga, tarif pengiriman, dan total biaya. Terdapat navigasi finish order untuk melanjutkan pada proses pembayaran customer.

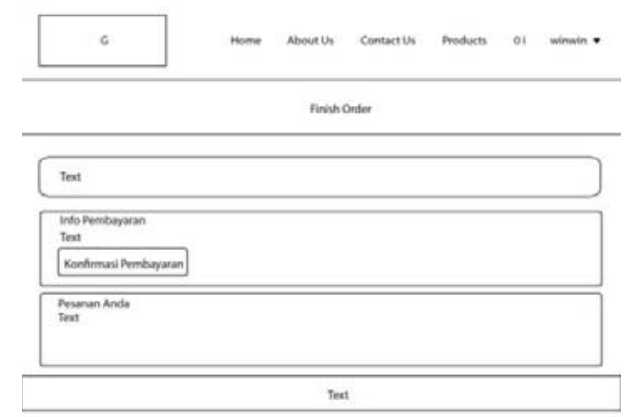

Gambar 10. Halaman Finish Order

Pada tampilan halaman finish order ini menampilkan tampilan mengenai informasi tentang informasi pembayaran customer, berupa nomor rekening tujuan yang akan di kirim oleh customer, menampilkan informasi mengenai kode pemesanan customer. 


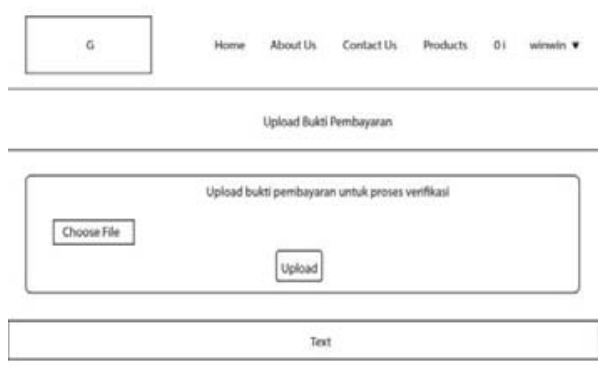

Gambar 11. Halaman Upload

Pada tampilan mockup upload bukti pembayaran ini menampilkan tampilan mengenai proses verifikasi agar transaksi dapat di lakukan dengan waktu yang lebih cepat customer harus mengupload bukti pembayarannya

\section{HASIL DAN PEMBAHASAN}

\section{Hasil Tampilan}

Berdasarkan perancangan dalam penelitian ini diperoleh hasil implementasi berupa pengujian aplikasi e-commerce terhadap bisnis proses pada user.

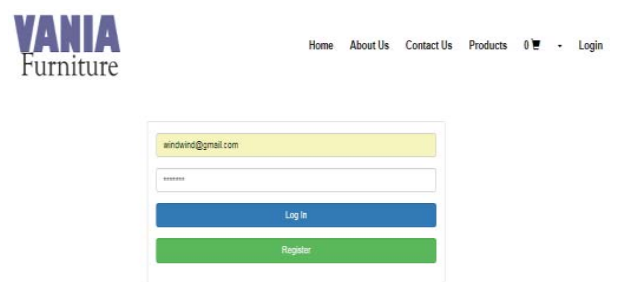

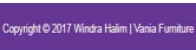

Gambar 12. Halaman Form Login

Pada gambar di atas, tampilan pada login menampilkan form akses masuk ke dalam web Vania Furniture dengan memasukan email dan password. bila user atau customer belum memiliki akun maka tidak dapat mengakses web tersebut.

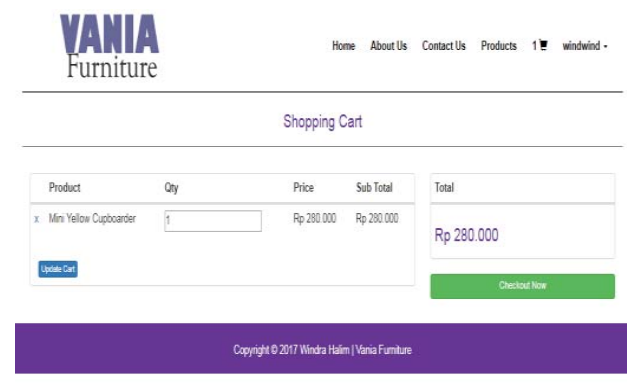

Gambar 13. Halaman Form Shopping Chart

Pada gambar di atas, tampilan pada shopping cart menampilakan form keranjang belanja, keranjang belanja ini menampung daftar produk yang ingin di beli oleh customer, customer juga dapat mengupdate jumlah barang yang sudah di masukkan kedalam keranjang belanja, selain itu customer juga dapat menghapus produk yang sudah ada di dalam daftar keranjang belanja tersebut. Selain itu daftar keranjang belanja ini juga menampilkan informasi harga produk dan total harga produknya.

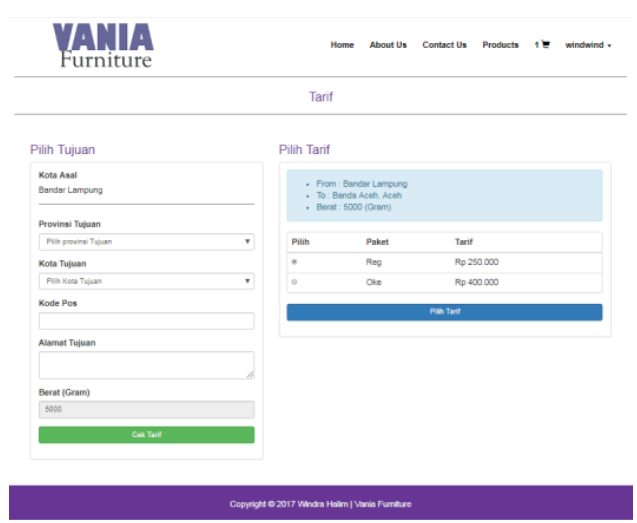

Gambar 14. Halaman Form Tarif

Pada gambar di atas, tampilan pada pilih tarif menampilakan form pemilihan jenis paket pengiriman dan tarif, setelah button cek tarif di klik maka kota asal, provinsi, kota, dan berat produk akan tampil. Serta pemilihan jenis paket berdasarkan provinsi dan kota tujuan dengan tarif sesuai tujuan pengiriman.

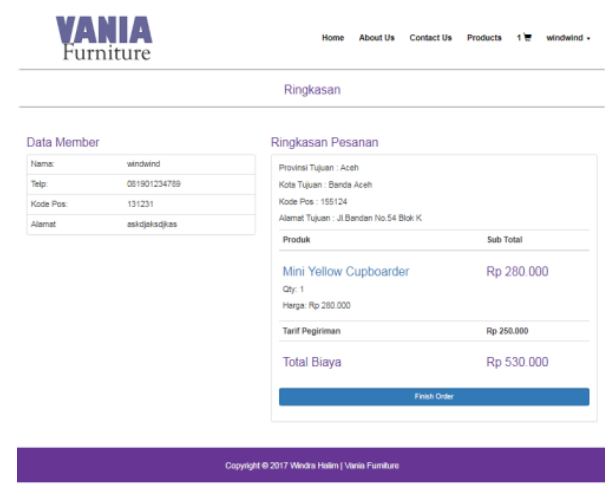

Gambar 15. Halaman Form Ringkasan 
Pada gambar di atas, tampilan pada ringkasan menampilakan form data member/customer berisi nama, nomor telepon, kode pos, dan alamat dari customer. Pada form ringkasan pesanan terdapat informasi provinsi, kota, kode pos, alamat tujuan. Selain itu terdapat nama, jumlah produk, harga, tarif pengiriman, dan total biaya yang harus di bayar oleh customer, informasi yang di tampilkan pada form ini bertujuan agar customer yakin dengan produk yang di pilih beserta tariftarif yang harus di bayar.

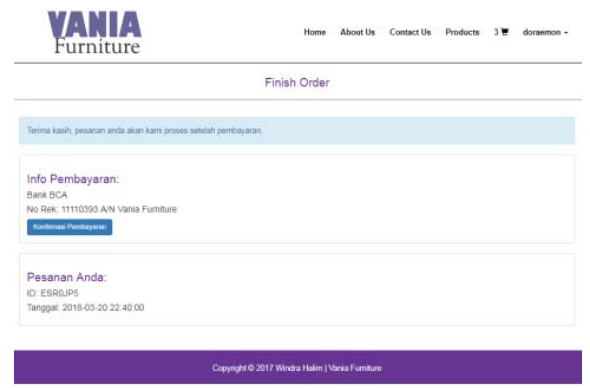

Gambar 16. Halaman Form Finish Order

Pada gambar di atas, tampilan pada finish order menampilakan form konfirmasi pembayaran, customer harus mengkonfirmasi pembayaran agar mendapat menyatakan bahwa pesanan yang sudah di order telah di bayar. Customer di haruskan mentransfer tagihan pada nomor rekening yang telah di sediakan. Ada juga tampilan kode dan tanggal pemesanan yang bertujuan untuk penampilan detail pesanan customer.

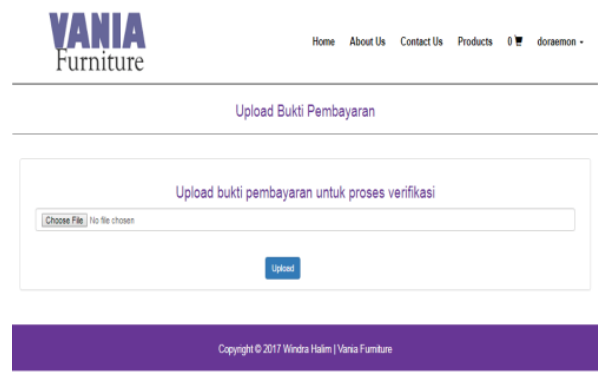

Gambar 17. Halaman Form Upload

Pada gambar di atas, tampilan pada upload bukti pembayaran menampilakan form upload bukti pembayaran untuk proses verifikasi agar admin dapat mengapprove pembayaran yang di lakukan oleh customer.

\section{KESIMPULAN DAN SARAN}

\section{Kesimpulan}

Berdasarkan perancangan Aplikasi E-commerce pada toko Vania Furniture, maka diperoleh kesimpulan sebagai berikut:

3. Aplikasi yang telah dibuat berhasil memberikan proses tampilan sistem berbasis web sehingga dengan sudah di terapkannya sistem berbasis web dapat sangat menunjang untuk perluasan jangkauan bisnis.

4. Proses transaksi yang dilakukan antara customer dan toko di lakukan dengan cara yang lebih cepat dan juga efektif.

5. Aplikasi yang dibuat dapat menghasilkan data penjualan pada toko Vania Furniture sehingga owner dapat dengan mudah melihat laporan penjualan.

\section{Saran}

Perancangan Aplikasi E-commerce pada toko Vania Furniture telah mencukupi kebutuhan dari permasalahan pada toko Vania Furniture, teteapi masih perlu adanya tambahan yang perlu di lakukan:

7. Aplikasi E-commerce pada toko Vania Furniture memerlukan maintenance yang di lakukan secara berkala agar kinerja sistem dapat terus berjalan dengan baik.

8. Perlu adanya tambahan human resource di bidang IT dan marketing untuk mendukung perkembangan aplikasi pada Vania Furniture dalam maintenance dan pemasaran.

9. Perlu adanya tambahan fitur retur pembelian untuk menambah kepuasan pelanggan dalam menggunakan aplikasi e-commerce Vania Furniture.

\section{DAFTAR PUSTAKA}

Alsmadi Izzat (2012). Advanced Automated Software Testing: Frameworks for Refined Practice. Published in the United States of Americe by Information Science Reference (an imprint of IGI Global). 
Coronel Carlos, Steven Moris (2016). Database Systems: Design, Implementation, \& Management. Course Technology.

Kosasi Sandy (2015). Peracangan Sistem Informasi E-Commerce Untuk Memperluas Pasar Produk Oleh Oleh Khas Pontianak. Jurnal SNASTIA_ 2015.

Kosasi Sandy (2015). Peracangan Sistem E-Commerce Untuk Produk Pembuatan Kue. Jurnal CSRID Journal, Vol.7 No.1 Februari 2015.

Larsen Rob (2013). Beginning HTML and CSS. John Wiley \& Sons, inc., Indianapolis, Indiana.

M. Roth Roberta, Alan dennis, Barbara haley wixom (2013). System Analysis and Design 5th edition. John wiley \& sons singapore pte. Ltd.Steven Suehring,

Orr Eli, Yehuda Zadik (2013). Programming with CodeIgniter MVC. Packt Publishing Ltd. 35 Livery Street, Birmingham B3 2PB, UK.

Rainer Jr R.Kelly,Brad Prince, dan Casey Cegielski (Rainer, Prince, Cegielski) (2015). Introduction to information systems. John Wiley \& Sons Singapore Pte. Ltd.

Tarr Andrea (2012). PHP and MySQL 24Hour Trainer. John Wiley \& Sons, inc., Indianapolis, Indiana.

Tegarden David, Alan Dennis, Barbara Haley Wixom (2013). Systems Analysis and Design with UML. John Wiley \& Sons Singapore Pte. Ltd.

Valade Janet (2013). PHP, MySQL, JavaScript \& HTML5 ALL-IN-ONE FOR DUMMIES.John Wiley \& Sons, inc., Hoboken, New Jersey. 